\title{
Synthesis and characterization of sodium-lithium niobate ceramic structures and their composites with biopolymers
}

\author{
Thomas V. MATHEW, Sunny KURIAKOSE ${ }^{*}$ \\ Research and Post Graduate Department of Chemistry, St. Thomas College, Pala, Arunapuram P.O., \\ Kottayam, Kerala, India
}

Received: October 02, 2012; Revised: December 07, 2012; Accepted: December 08, 2012

CThe Author(s) 2013. This article is published with open access at Springerlink.com

\begin{abstract}
Ceramic powders of $\mathrm{Na}_{1-x} \mathrm{Li}_{x} \mathrm{NbO}_{3}$ (LNN) have been synthesized by an aqueous sol-gel route. These solid solutions were prepared from $\mathrm{Na}-\mathrm{Li}-\mathrm{Nb}$ precursor gel. The precursor was synthesized from Na-EDTA, Li-EDTA and Nb-citrate complexes and they acted as the source of $\mathrm{Na}$, $\mathrm{Li}$ and $\mathrm{Nb}$, respectively. Citric acid and ethylenediaminetetraacetic acid (EDTA) were used as the chelating agents for $\mathrm{Na}, \mathrm{Li}$ and $\mathrm{Nb}$. The precursor gel was calcinated on a muffle furnace at $750{ }^{\circ} \mathrm{C}$ for one hour and this provided the ceramic structures. Composites of LNN-biopolymers were prepared by the encapsulation of the ceramic structures into the biopolymeric scaffolds. The ceramic structures and composites were characterized by FTIR, NMR, TG and SEM analysis.
\end{abstract}

Keywords: ceramic structures; sol-gel chemistry; encapsulation; thermo gravimetric analysis (TGA)

\section{Introduction}

The system $\mathrm{Na}_{1-x} \mathrm{Li}_{x} \mathrm{NbO}_{3}$ is a solid solution of sodium niobate and lithium niobate, named LNN, displaying dielectric characteristics different from the two pure niobates. Lithium niobate is ferroelectric at room temperature showing a rhombohedral structure, whereas sodium niobate is antiferroelectric showing an orthorhombic structure. The presence of small amounts of $\mathrm{LiNbO}_{3}$ dissolved in $\mathrm{NaNbO}_{3}$ modifies its dielectric characteristics [1]. Sodium niobate, $\mathrm{NaNbO}_{3}$, is a dielectric material with a perovskite-type structure. At room temperature, it has an orthorhombic structure, and shows antiferroelectric behavior, with a Curie temperature of $360{ }^{\circ} \mathrm{C}$ [2]. Solid solution with $\mathrm{LiNbO}_{3}$

* Corresponding author.

E-mail: sunnykuriakose30@gmail.com can exhibit piezoelectric, ferroelectric, pyroelectric and electro-optic behavior [3].

The chemical and microstructural homogeneity of alkali metal niobates affects critically the electro-optic behavior, and therefore the synthesis of ceramic powders with good stoichiometry, homogeneity and sinterability is necessary to develop $\mathrm{NaNbO}_{3}$ ceramics [4]. Traditional solid-state preparation methods lead to poor compositional homogeneity, especially because of the easy volatilization of the alkali metal, since high temperatures are required for synthesis and sintering. Powder synthesis using solution techniques allows a better mixing of the constituent elements and thus a better reactivity of the mixture to obtain pre-reaction products at lower temperatures, and can produce chemically homogeneous powders with fine particle size and high reactivity, suitable for the preparation of dense ceramics with homogeneous microstructure. One such 
technique for the low temperature synthesis of oxides is the so-called amorphous complex method [5]. This technique is mainly based on the formation of soluble complexes in solution, followed by elimination of the solvent, resulting in a gel that keeps the random distribution of cations of the starting solution. The organic fraction of this gel is removed by heat process, resulting in very fine, homogeneous and reactive crystalline oxide powders at temperatures lower than those used in the solid-state reaction. However, few studies have been reported on the synthesis of $\mathrm{NaNbO}_{3}$ powders, or the preparation of $\mathrm{NaNbO}_{3}$ polycrystalline ceramics using wet chemical methods: a polymeric precursor route using Pechini method [4], or preparation from solution using oxalic acid [6].

Lignin is a natural composite material in all vascular plants, providing the plant with strength and rigidity. The word lignin is derived from the Latin word lignum meaning wood. It is a main component of vascular plants. Indeed, lignin is second only to polysaccharides in natural abundance, contributing $24 \%-33 \%$ and $19 \%-28 \%$, respectively, to dry wood weights of normal softwoods and temperate-zone hardwoods [7]. By decreasing water permeation across the cell wall, lignin renders the plant resistant to biodegradation as well as to environmental stresses. Lignin is an amorphous, aromatic, water insoluble, heterogeneous, threedimensional, and cross-linked polymer with low viscosity. The molecular mass of lignin is high (600$1000 \mathrm{kDa}$ ), although not uniform, varying greatly within isolated samples. The molecular mass of lignin is thus difficult to determine, and the use of a conventional formula is not possible. Lignin is highly reduced and its carbon content is $50 \%$ higher than that of polysaccharides [8], which makes lignin energy-rich [9].

Bovine serum albumin (BSA) is a globular protein with 66500 Da molecular mass, consisting of 583 amino acid residues. The protein net charge is -17 at neutral $\mathrm{pH}$. Seventeen disulfide bridges help to maintain the globular structure and form the three homologous structural domains. Serum albumins are the carrier proteins of blood. The soft globular structure easily undergoes conformational changes, which make easily for the protein to accommodate wide variety of solution species, and form complexes with fatty acids, lipids, dissolved small cations and different drug molecules and carry them in the bloodstream. The secondary structure is essentially $\alpha$-helical $[10,11]$. The tendency of BSA to aggregate into macromolecular assemblies is related to conformational changes [12,13]. Proteins, such as albumin, possess a strong tendency toward structural rearrangements when adsorbed on a nonbiological surface, depending on the surface properties [14-16].

In recent years, there has been an increasing interest for massive or local doping of lithium niobate in order to extend its functionality. Combining the lithium niobate host properties with the spectroscopic properties of the dopants, higher component integration may be achieved; this, of course, is imposing increasingly demanding conditions to the materials and fabrication techniques. In the present work, we report the synthesis of Na-doped nano-sized lithium niobate and encapsulation of these systems into biopolymers.

For this purpose, we synthesized ceramics of sodium-lithium niobate, $\mathrm{Na}_{1-x} \mathrm{Li}_{x} \mathrm{NbO}_{3}(x=0.06,0.12)$ using polymer precursor method [4], which is modified by new chelating agents. Nano-sized ceramic particles are of great interest in modern chemical research due to their unique electrical, magnetic, optical and other properties, which are distinct from macro-sized materials. Nano-sized ceramic particles are so unstable that if their surfaces touch, they will fuse together, lose their special shape and properties. The development of polymer stabilized ceramic particles is one of the most promising solutions to the stability problem.

\section{Materials and methods}

\subsection{Reagents}

All the reagents were of analytical grade. All the solvents were purchased from Merck, India, and used without further purification. All aqueous solutions were prepared with distilled and deionized water. Bovine serum albumin (BSA, $M W=66 \mathrm{kDa}$ ) was purchased from Sigma (A-7030), USA, and the necessary dilutions were made from the stock with deionized water. Hydrofluric acid, citric acid monohydrate, sodium nitrate $\left(\mathrm{NaNO}_{3}\right)$, lithium chloride $(\mathrm{LiCl})$ and ethylenediaminetetraacetic acid (EDTA) were obtained from Merck, India. Lithium nitrate $\left(\mathrm{LiNO}_{3}\right)$ and niobium pentoxide $\left(\mathrm{Nb}_{2} \mathrm{O}_{5}\right)$ were purchased from Himedia, India.

\section{2 Instrumentation}

UV visible analysis was carried out on a Shimadzu-160 
UV-VIS Spectrophotometer operating in the range of $190-1100 \mathrm{~nm}$. FTIR spectra were recorded on a Thermo Nicolet, Avatar 370 Spectrophotometer in the spectral range of $4000-400 \mathrm{~cm}^{-1}$ with $0.9 \mathrm{~cm}^{-1}$ resolution. Proton nuclear magnetic resonance $\left({ }^{1} \mathrm{H}\right.$ NMR) measurements were performed on a Bruker Avance III, $400 \mathrm{MHz}$ NMR Spectrometer using DMSO as the solvent. Thermo gravimetric analysis (TGA) was performed on Perkin Elmer, Diamond TG/DTA at temperature ranging between ambient and $1200{ }^{\circ} \mathrm{C}$ at $10{ }^{\circ} \mathrm{C} / \mathrm{min}$ heating rate under nitrogen atmosphere. The morphological features of ceramic powders and polymer dispersed products were characterized by JEOL JSM-6390LV Scaning Electron Spectroscope and JEOL JEM 2011 Transmission Electron Microscope.

\section{3 Synthesis of LNN ceramic structures}

The starting materials for the synthesis were $\mathrm{NaNO}_{3}$, $\mathrm{LiNO}_{3}, \quad \mathrm{Nb}_{2} \mathrm{O}_{5}, \quad$ ethylenediaminetertraacetic acid (EDTA), ammonia solution and citric acid. The citric acid and EDTA acted as the chelating agents.

\section{First stage}

The first stage of the synthesis is the preparation of Na-EDTA and Li-EDTA complexes. Transparent Na-EDTA and Li-EDTA complexes were prepared by the reaction of aqueous solutions of $\mathrm{NaNO}_{3}$ and $\mathrm{LiNO}_{3}$ with EDTA solution.

\section{Second stage}

In the second stage, $\mathrm{Nb}$-citrate complex was prepared by heating $\mathrm{Nb}_{2} \mathrm{O}_{5}$ dissolved in $\mathrm{HF}$ for $48 \mathrm{~h}$ in the form of $\mathrm{NbOF}_{5}{ }^{2+}$ or $\mathrm{NbF}_{7}^{2+}$. Aqueous solution of ammonium oxalate was added to the solution, keeping the oxalate ions in excess. Then ammonia solution was added with continuous stirring for a precipitation of hydrous niobium oxide $\left(\mathrm{Nb}_{2} \mathrm{O}_{5} \cdot n \mathrm{H}_{2} \mathrm{O}\right)$. The precipitation was aged at $80{ }^{\circ} \mathrm{C}$ for $12 \mathrm{~h}$, after which it was filtered and washed with deionized water to make fluoride free. The hydrous niobium oxide was then dissolved in aqueous solution of citric acid by continuous stirring and heating at $60{ }^{\circ} \mathrm{C}$ to form a transparent pale yellow $\mathrm{Nb}$-citrate complex.

\section{Third stage}

In the third stage, $\mathrm{Na}_{1-x} \mathrm{Li}_{x} \mathrm{NbO}_{3}(x=0.06,0.12)$ ceramic powders were prepared by mixing stoichiometric amounts of Na-EDTA, Li-EDTA, and $\mathrm{Nb}$-citrate solutions, followed by addition of citric acid in the molar ratio citric acid: $\mathrm{Nb}=3: 1$. The $\mathrm{pH}$ was adjusted to 8 by the addition of ammonia solution and then $\mathrm{Na}-\mathrm{Li}-\mathrm{Nb}$ precursor solution was obtained with continuous stirring. The $\mathrm{Na}-\mathrm{Li}-\mathrm{Nb}$ precursor solution was heated at $80{ }^{\circ} \mathrm{C}$ for $24 \mathrm{~h}$ to produce a gelatinous precursor which was then calcined between $400{ }^{\circ} \mathrm{C}$ and $750{ }^{\circ} \mathrm{C}$ for $2 \mathrm{~h}$ in air in a muffle furnace to form LNN ceramic structures. The flow chart of the synthesis of LNN ceramic structures is given in Fig. 1.

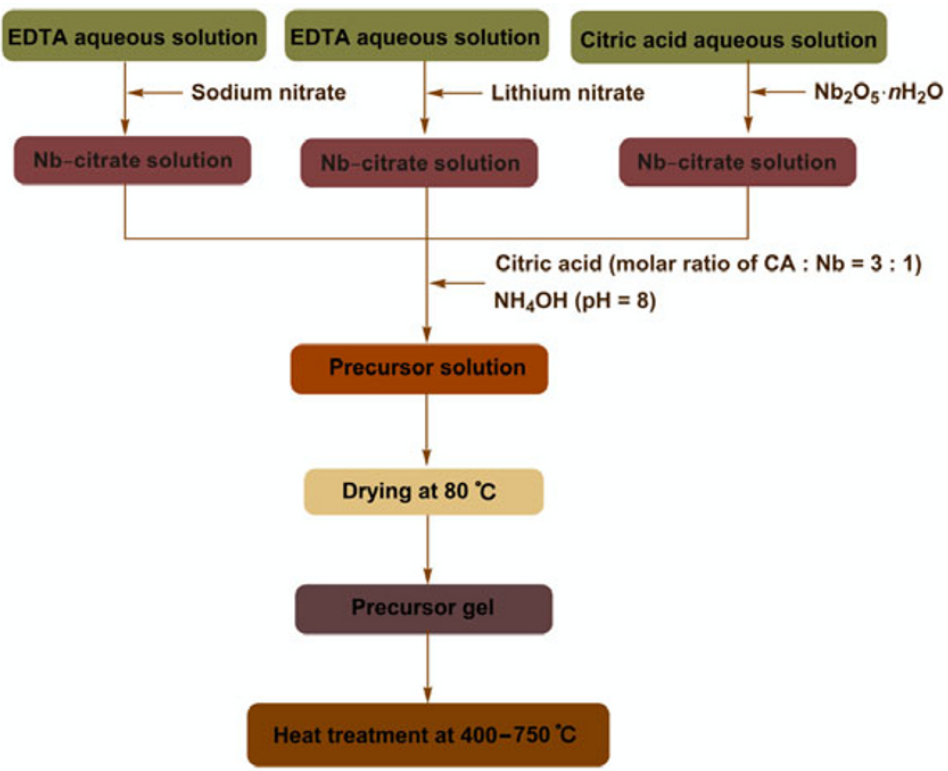

Fig. 1 Synthesis of LNN nanostructures. 


\section{4 Encapsulation of LNN ceramic structures into biopolymers}

Sodium-lithium niobate ceramic structures were encapsulated into lignin and BSA at room temperature. LNN nanoparticles $(50 \mathrm{mg}$ ) were dissolved in doubly deionized water $(15 \mathrm{ml})$ and quickly added to lignin and BSA $(500 \mathrm{mg})$ dissolved in solvents (lignin dissolved in $15 \mathrm{ml}$ dimethyl formamide, and BSA in $15 \mathrm{ml}$ doubly deionized water). The reaction mixture was stirred at room temperature for $4 \mathrm{~h}$. The solvents were removed on a vacuum rotory flash evaporator and further washed with water to remove excess $\mathrm{LNN}$ nanoparticles, dried and kept under vacuum.

\section{Results and discussion}

\section{1 Characterization of LNN nanostructures}

Sodium-lithium niobate nanostructures obtained were characterized by XRD, SEM, TEM and TG analysis.

\section{XRD analysis}

The annealed samples were investigated by X-ray powder diffraction, using $\mathrm{Cu} \mathrm{K} \alpha$ radiation. The crystalline size was estimated using Scherrer equation [17],

$$
L=\frac{\kappa \lambda}{\beta \cos \theta}
$$

where $L$ is the mean diameter of a crystal, $\kappa$ is a geometry factor $(0.94), \lambda$ is the wavelength used (1.5406 $\AA$ ), $\beta$ is a full width at half maximum (FWHM) and $\theta$ is Bragg angle. The corresponding crystalline size calculated using Scherrer equation is $28 \mathrm{~nm}$. The XRD pattern of the annealed sample is shown in Fig. 2.

\section{Scanning electron microscopy (SEM)}

Figure 3 demonstrates a typical SEM image of sodium-lithium niobate nanostructures.

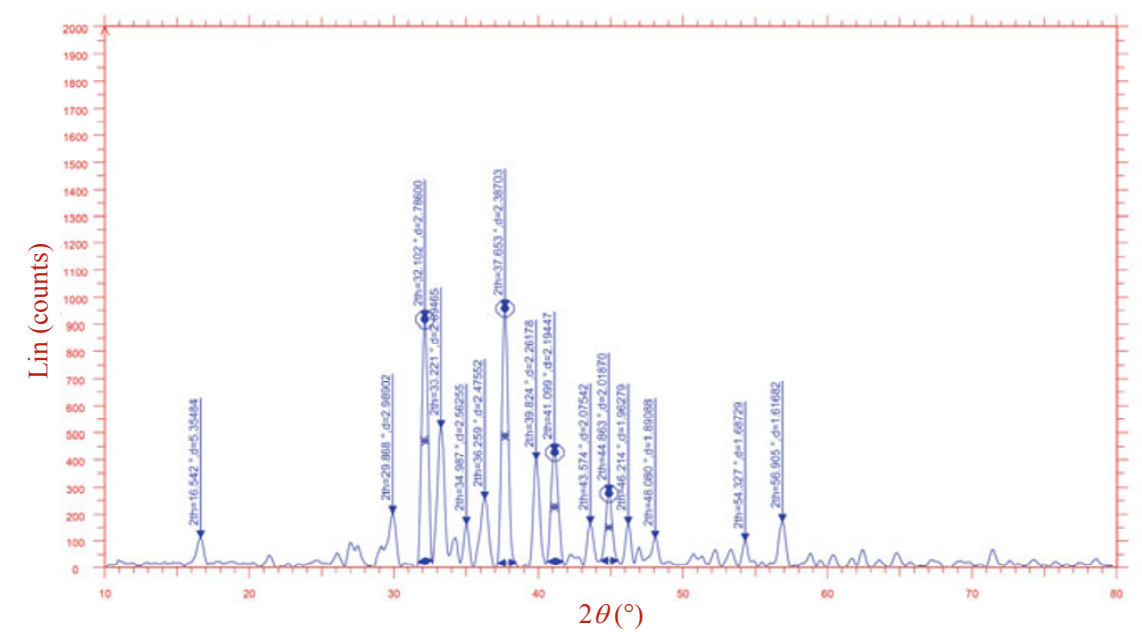

Fig. 2 XRD patterns of the annealed sample of LNN nanostructures.

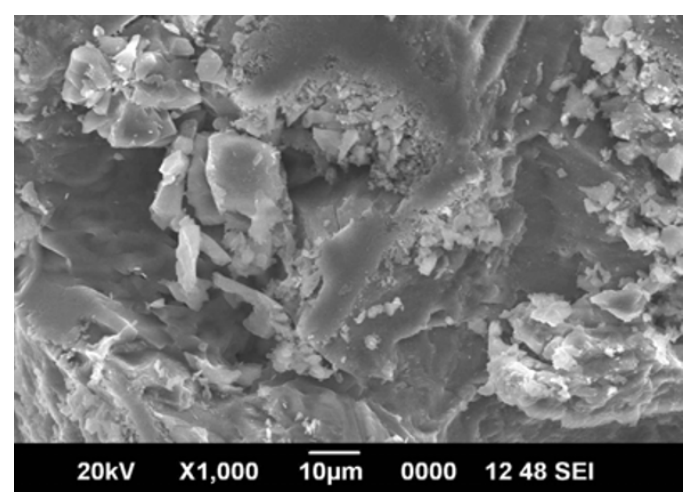

Fig. 3 SEM photograph of LNN nanostructures.

\section{Transmission electron microscopy (TEM)}

The formation of sodium-lithium niobate nanostructures was further confirmed by TEM analysis. Figure 4 shows the TEM image of LNN nanostructures produced. The photograph shows that all the particles are almost spherical in shape and have narrow size distribution.

\section{Thermal analysis}

The TG of sodium-lithium niobate nanostructures has two mass-loss steps. In the first step, the initial decomposition temperature is $T_{\mathrm{i}}=88.51{ }^{\circ} \mathrm{C}$, temperature at which maximum degradation takes place is $T_{\mathrm{m}}=126.15^{\circ} \mathrm{C}$, and the enthalpy change $(\Delta H)$ 


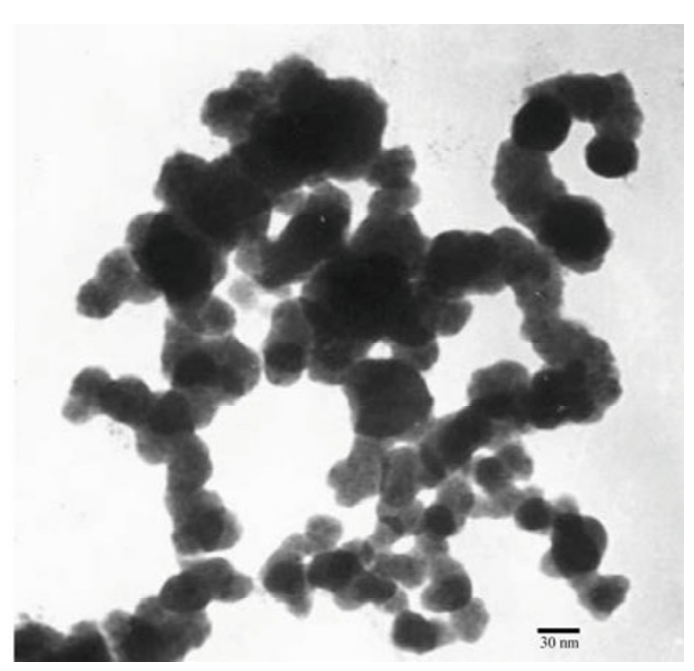

Fig. 4 TEM micrograph of LNN nanostructures.

associated with this event is $720.3295 \mathrm{~J} / \mathrm{g}$. This thermal event is due to the loss of moisture. In the second thermal event, the initial decomposition temperature $T_{\mathrm{i}}=797.68^{\circ} \mathrm{C}$, temperature at which maximum degradation takes place is $T_{\mathrm{m}}=804.88^{\circ} \mathrm{C}$ and the enthalpy change $(\Delta H)$ associated with this event is $144.3402 \mathrm{~J} / \mathrm{g}$. Figure 5 shows the TG curve of LNN nanostructures.

\section{2 Characterization of lignin-LNN}

\section{FTIR spectral analysis}

The IR spectrum of the product was recorded as $\mathrm{KBr}$ pellets in the scanning range of $4000-400 \mathrm{~cm}^{-1}$ and the spectrum shows important signals such as: $3356.22 \mathrm{~cm}^{-1}$ (O-H stretching), $2818.20 \mathrm{~cm}^{-1}$ (aromatic $\mathrm{C}-\mathrm{H}$ stretching), $2730.54 \mathrm{~cm}^{-1}$ (aliphatic $\mathrm{C}-\mathrm{H} \quad$ stretching $), \quad 1652.72 \mathrm{~cm}^{-1} \quad(\mathrm{C}=\mathrm{O} \quad$ stretching vibrations), $1581.00 \mathrm{~cm}^{-1}$ (aromatic $\mathrm{C}=\mathrm{C}$ stretching vibrations), $1263.20 \mathrm{~cm}^{-1}$ (asymmetric $\mathrm{C}-\mathrm{O}-\mathrm{C}$ stretching vibrations), $1104.67 \mathrm{~cm}^{-1}$ (symmetric $\mathrm{C}-\mathrm{O}$ stretching vibrations $-\mathrm{OH}$ groups), $1029.28 \mathrm{~cm}^{-1}$ (symmetric $\mathrm{C}-\mathrm{O}-\mathrm{C}$ stretching vibrations), $659.86 \mathrm{~cm}^{-1}$ ( $\mathrm{Nb}-\mathrm{O}$ stretching vibrations). The spectrum is shown in Fig. 6.

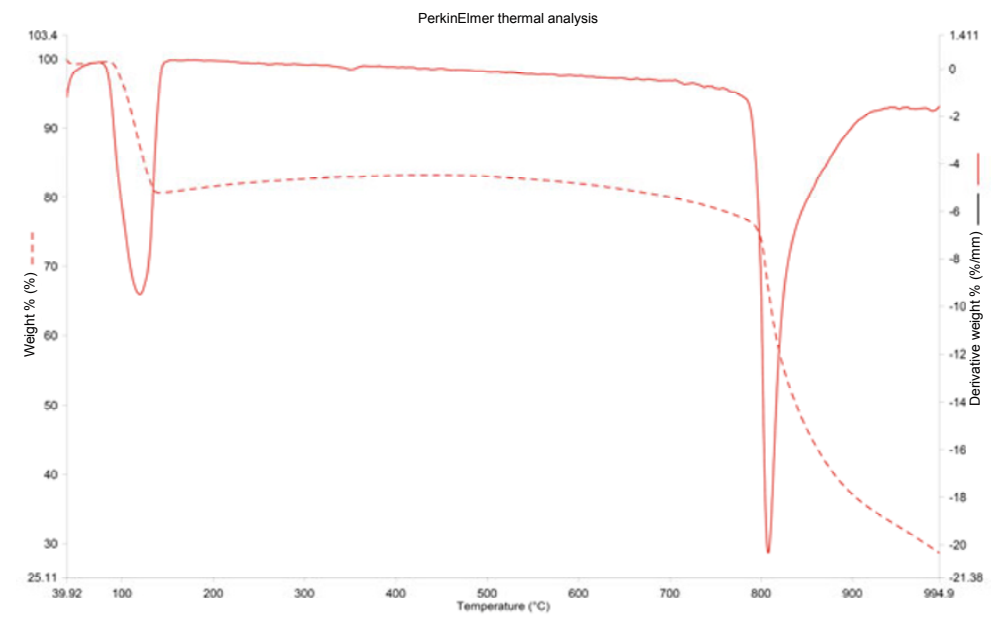

Fig. 5 TG curve of LNN nanostructures.

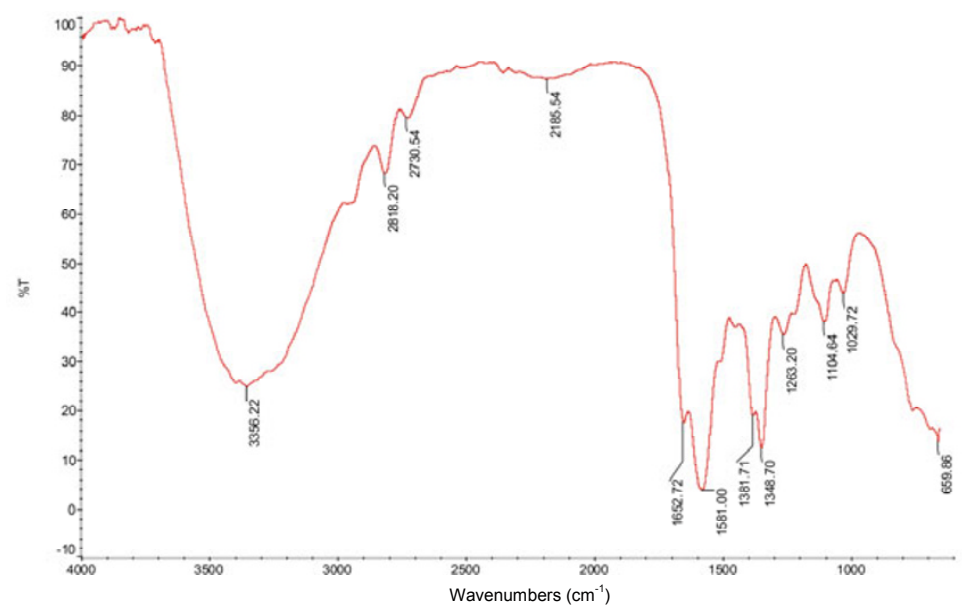

Fig. 6 FTIR spectrum of lignin-encapsulated LNN. 


\section{${ }^{1}$ H NMR spectral analysis}

The proton NMR spectrum of the product was recorded in DMSO in a $400 \mathrm{MHz}$ NMR spectrophotometer and the spectrum shows signals at $\delta 8.381(\mathrm{~s}, 1 \mathrm{H}$,
-CHO proton of lignin), $\delta$ 7-8 (aromatic protons of lignin), $\delta$ 3.20-4.14 (aliphatic and aromatic - $\mathrm{HO}$ protons), $\delta$ 2.1-2.9 (multiplet $-\mathrm{CH},-\mathrm{CH}_{2}$ and $-\mathrm{CH}_{3}$ protons). The NMR spectrum is given in Fig. 7.

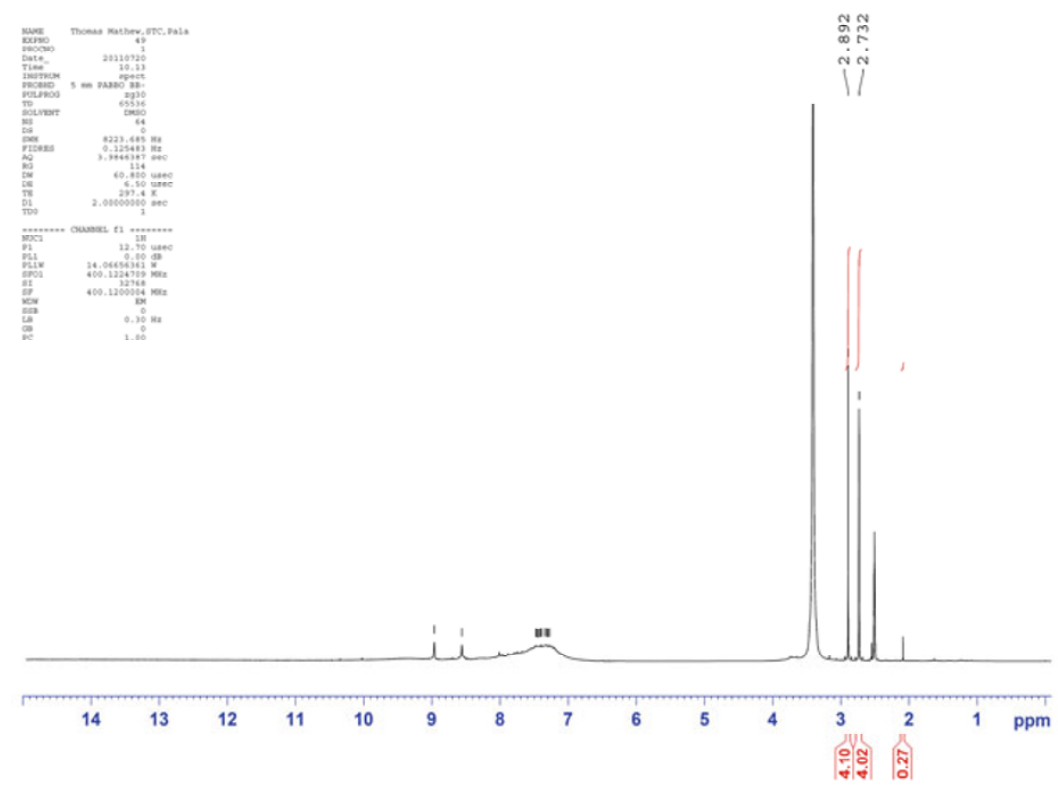

Fig. $7 \quad{ }^{1} \mathrm{H}$ NMR spectrum of lignin-encapsulated LNN.

\section{UV-VIS spectral analysis}

The UV-VIS spectrum of encapsulated product was recorded in dimethyl formamide at room temperature. The UV-VIS spectrum shows one absorption band corresponding to the aromatic rings of lignin. The UV-VIS spectrum is shown in Fig. 8.

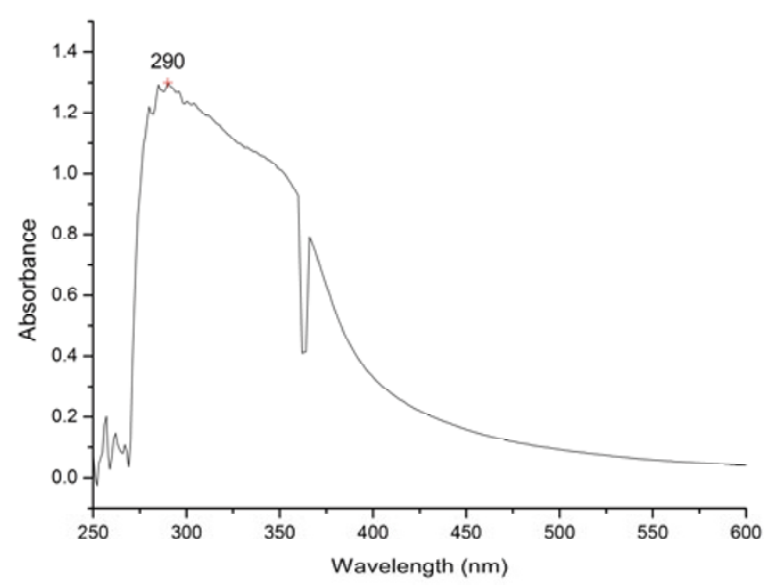

Fig. 8 UV-VIS spectrum of lignin-encapsulated LNN.

\section{Scanning electron microscopy (SEM)}

Figure 9 depicts the SEM image of ligninencapsulated LNN. Nanoparticles are well distributed into the polymer matrix and are compatible with the lignin matrix.

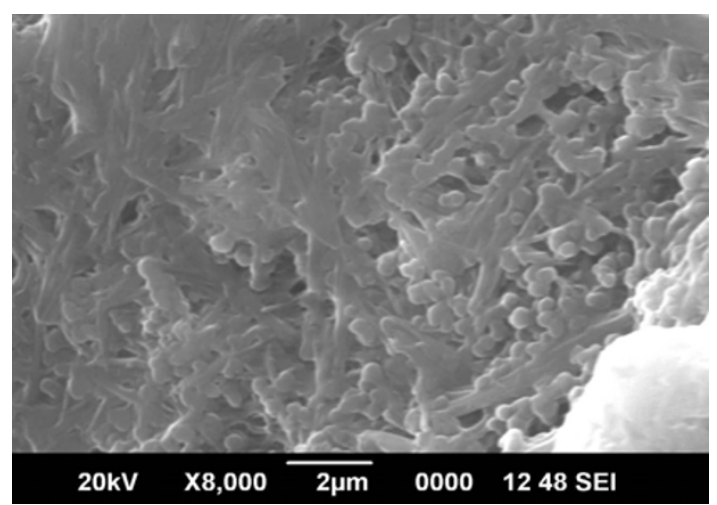

Fig. 9 SEM photograph of lignin-encapsulated LNN.

\section{Thermal analysis}

DSC curve of lignin-encapsulated LNN (Fig. 10) shows two endotherms. The first endotherm shows the peak temperature $\left(T_{\mathrm{p}}\right)$ at $123.42{ }^{\circ} \mathrm{C}$, onset temperature $\left(T_{\mathrm{o}}\right)$ at $117.05{ }^{\circ} \mathrm{C}$, endset temperature $\left(T_{\mathrm{e}}\right)$ at $166.43{ }^{\circ} \mathrm{C}$ and $\Delta T\left(=T_{\mathrm{p}}-T_{\mathrm{o}}\right)$ at $6.37{ }^{\circ} \mathrm{C}$. The second endotherm shows the peak temperature $\left(T_{\mathrm{p}}\right)$ at $236.95^{\circ} \mathrm{C}$, onset temperature $\left(T_{\mathrm{o}}\right)$ at $222.79{ }^{\circ} \mathrm{C}$, endset temperature $\left(T_{\mathrm{e}}\right)$ at $243.89^{\circ} \mathrm{C}$ and $\Delta T\left(=T_{\mathrm{p}}-T_{\mathrm{o}}\right)$ at $14.16{ }^{\circ} \mathrm{C}$ also observed. There are four mass-loss events in the TG of lignin-encapsulated LNN: one in the temperature range between $100{ }^{\circ} \mathrm{C}$ and $130{ }^{\circ} \mathrm{C}$, and another in the range of $130-310{ }^{\circ} \mathrm{C}$; the third and fourth thermal events are 
observed at higher temperature regions. The maximum degradations $\left(T_{\mathrm{m}}\right)$ are observed at $672{ }^{\circ} \mathrm{C}$ and $735^{\circ} \mathrm{C}$ respectively. Figure 11 shows the TG curve of lignin-encapsulated LNN.

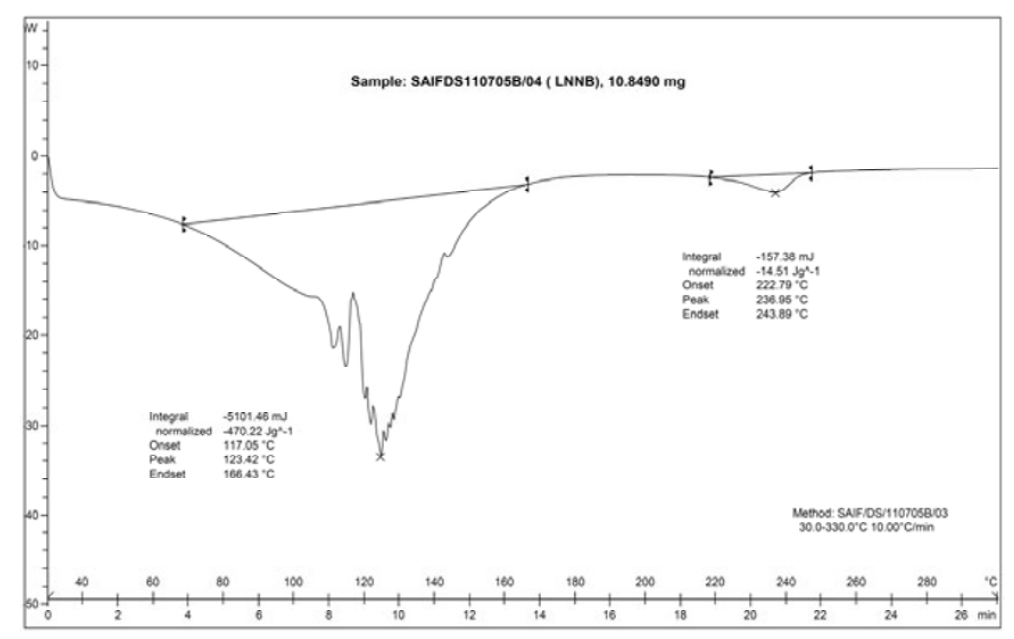

Fig. 10 DSC curves of lignin-encapsulated LNN.

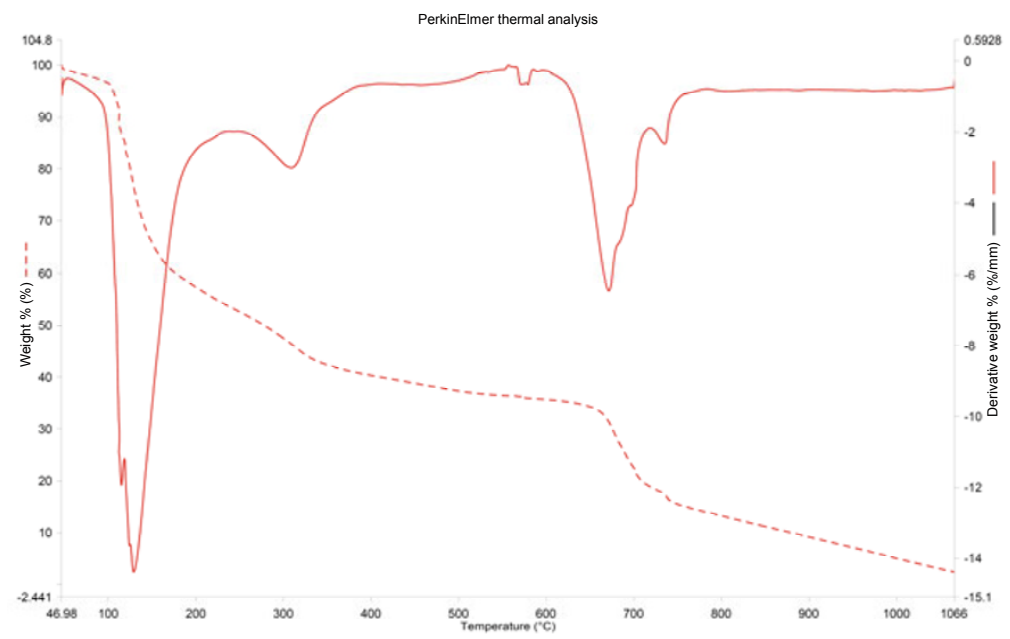

Fig. 11 TG curve of lignin-encapsulated LNN.

\section{3 Characterization of BSA-LNN}

\section{FTIR spectral analysis}

The IR spectrum of the product was recorded as $\mathrm{KBr}$ pellets in the scanning range of $4000-400 \mathrm{~cm}^{-1}$ and the spectrum shows important signals such as: $3450.26 \mathrm{~cm}^{-1}$ (O-H \& N-H stretching), $2924.01 \mathrm{~cm}^{-1}$ (- $\mathrm{CH}_{2}$-asymmetric stretching), $2858.40 \mathrm{~cm}^{-1}\left(-\mathrm{CH}_{2}-\right.$ symmetric stretching), $1631.65 \mathrm{~cm}^{-1}(\mathrm{C}=\mathrm{O}$ stretching), $1453.89 \mathrm{~cm}^{-1}$ (N-H bending), $1375.13 \mathrm{~cm}^{-1}$ (C-N stretching), $603.28 \mathrm{~cm}^{-1}$ (Nb-O stretching vibrations). The spectrum is shown in Fig. 12.

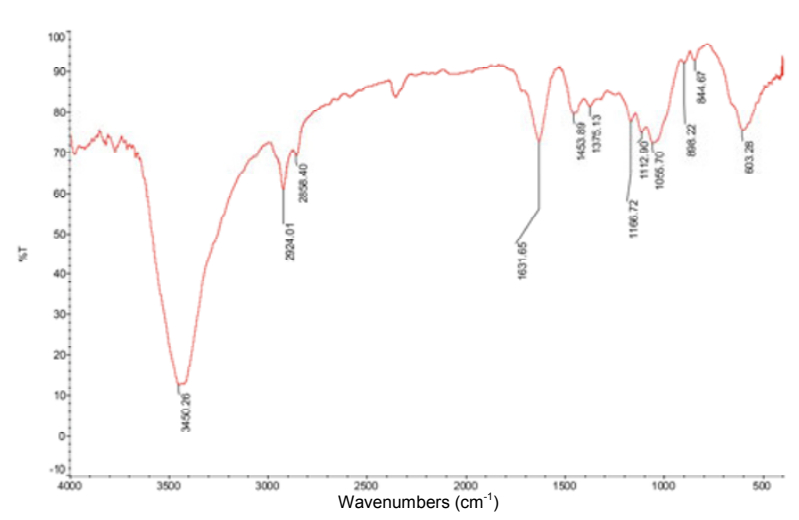

Fig. 12 FTIR spectrum of BSA-encapsulated LNN. 


\section{${ }^{1}$ H NMR spectral analysis}

The proton NMR spectrum of the product was recorded in DMSO in a $400 \mathrm{MHz}$ NMR spectrophotometer and the spectrum shows signals at $\delta$
6.722-8.499 (aromatic protons), $\delta \quad 6.1 \quad$ (-CONH proton), $\delta 0.8-2.5$ (multiplet $-\mathrm{CH}$ and $-\mathrm{CH}_{2}$ protons). The NMR spectrum is given in Fig. 13.

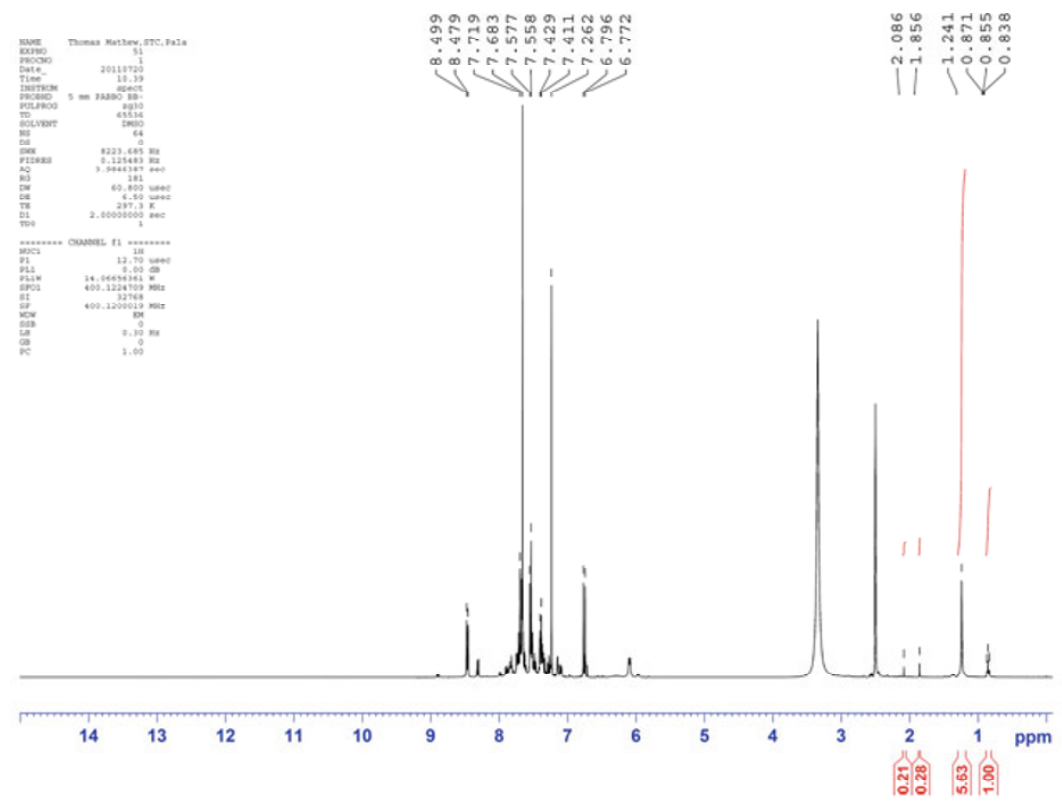

Fig. $13{ }^{1}$ H NMR spectrum of BSA-encapsulated LNN.

\section{UV-VIS spectral analysis}

The UV-VIS spectrum of the encapsulated product was recorded in deionized water at room temperature. The spectrum is given in Fig. 14. No characteristic peak is observed for sodium-lithium niobate nanostructures. A peak with $\lambda_{\max }=222 \mathrm{~nm}$ is caused by the $\pi-\pi^{*}$ transitions of aromatic amino acid residues.

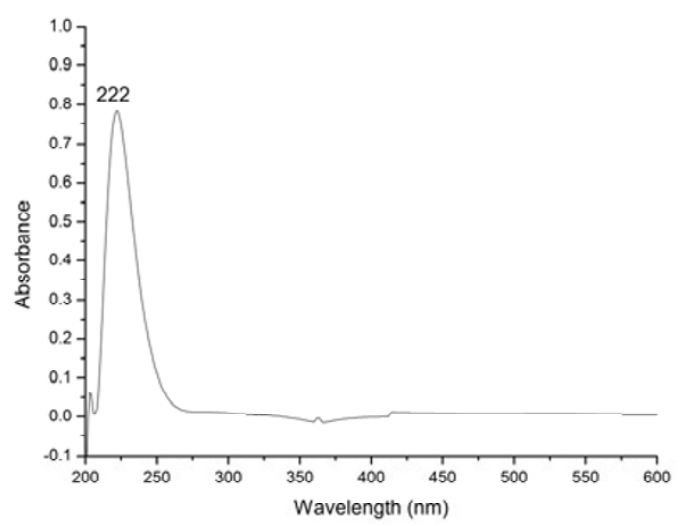

Fig. 14 UV-VIS spectrum of BSA-encapsulated LNN.

\section{Scanning electron microscopy (SEM)}

Figure 15 depicts the SEM image of BSAencapsulated LNN. Sodium-lithium niobate nanostructures are well dispersed into albumin and are stabilized by the amino groups.

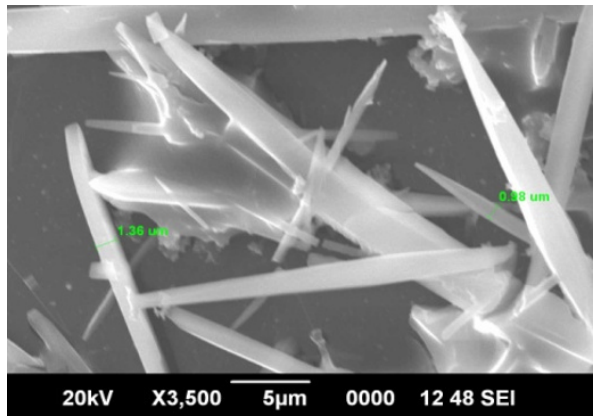

Fig. 15 SEM photograph of BSA-encapsulated LNN.

\section{Thermal analysis}

DSC curve of BSA-encapsulated LNN (Fig. 16) shows two endotherms. The first endotherm shows the peak temperature $\left(T_{\mathrm{p}}\right)$ at $80.82{ }^{\circ} \mathrm{C}$, onset temperature $\left(T_{\mathrm{o}}\right)$ at $63.83{ }^{\circ} \mathrm{C}$, endset temperature $\left(T_{\mathrm{e}}\right)$ at $99.28{ }^{\circ} \mathrm{C}$ and $\Delta T\left(=T_{\mathrm{p}}-T_{\mathrm{o}}\right)$ at $16.99^{\circ} \mathrm{C}$. The second endotherm has the peak temperature $\left(T_{\mathrm{p}}\right)$ at $107.36{ }^{\circ} \mathrm{C}$, onset temperature $\left(T_{\mathrm{o}}\right)$ at $103.58{ }^{\circ} \mathrm{C}$, endset temperature $\left(T_{\mathrm{e}}\right)$ at $113.00{ }^{\circ} \mathrm{C}$ and $\Delta T\left(=T_{\mathrm{p}}-T_{\mathrm{o}}\right)$ at $3.78{ }^{\circ} \mathrm{C}$. The TG of BSA-encapsulated LNN has several mass-loss events. Figure 17 shows the TG curve of BSA-encapsulated LNN. These steps are due to the denaturation of protein, decomposition of protein and change of crystal structure of sodium-lithium niobate nanostructures. 


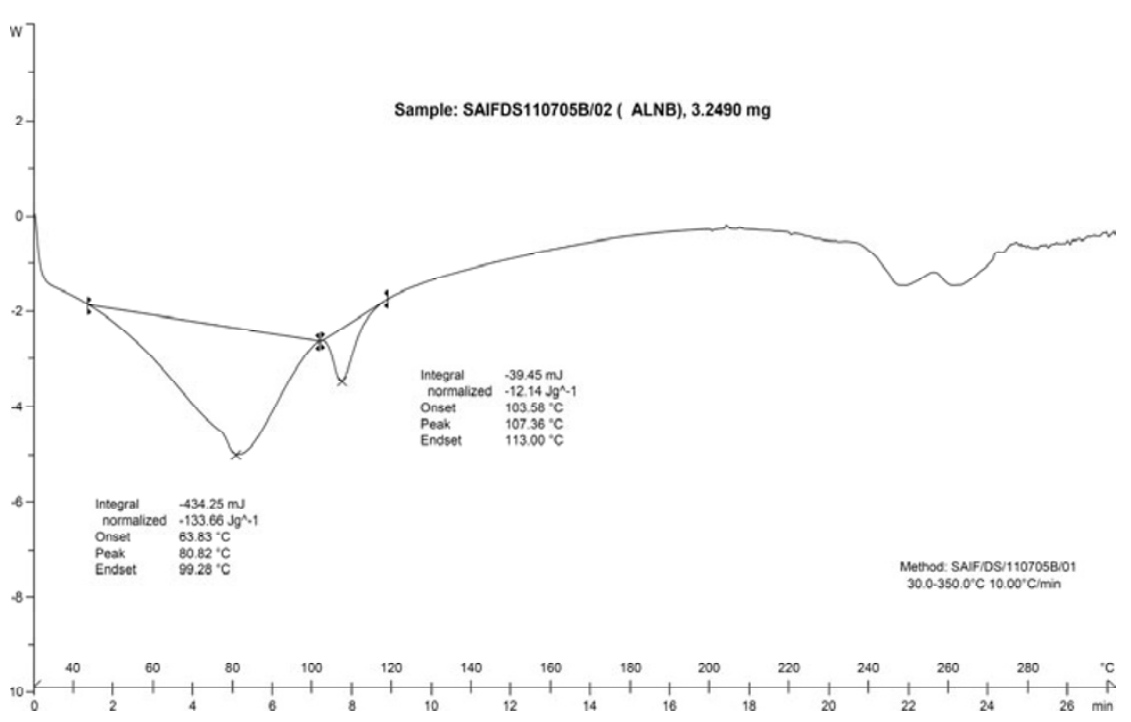

Fig. 16 DSC curve of BSA-encapsulated LNN.

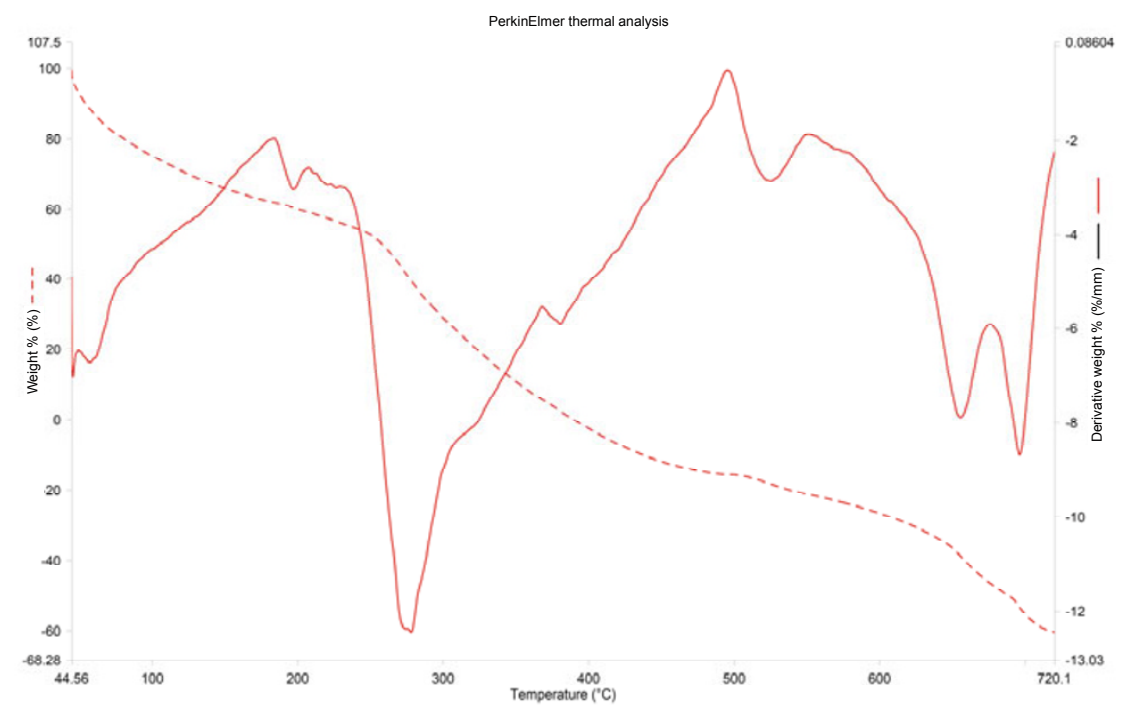

Fig. 17 TG curve of BSA-encapsulated LNN.

\section{Conclusions}

Sodium-lithium niobate (LNN) nanostructures were synthesized and characterized, and these nanostructures were encapsulated into the biopolymer matrices of lignin and bovine serum albumin (BSA). The encapsulations of LNN nanostructures into lignin and BSA enhance the stability of the nanostructures by preventing the formation of macro-sized particles from the nanostructured particles. The encapsulation of LNN nanostructures into biopolymer increases the biocompatibility of the nanostructures. The products were characterized by FTIR, ${ }^{1} \mathrm{H}$ NMR, UV-VIS, SEM, TG and DSC analysis. The annealed samples were investigated by X-ray powder diffraction, using $\mathrm{Cu} \mathrm{K} \alpha$ radiation. The crystalline size was estimated using Scherrer equation and found to be $28 \mathrm{~nm}$. The formation of LNN nanostructures was confirmed by SEM and TEM analysis. From the TEM analysis it was confirmed that the nanostructures are almost spherical in shape and have narrow size distribution. The TG of LNN nanostructures has two mass-loss steps. In the second thermal event, the initial decomposition temperature $T_{\mathrm{i}}=797.68{ }^{\circ} \mathrm{C}$, temperature at which maximum degradation takes place $T_{\mathrm{m}}=804.88^{\circ} \mathrm{C}$ and the enthalpy change $(\Delta H)$ associated with this event is $144.3402 \mathrm{~J} / \mathrm{g}$. The FTIR, ${ }^{1} \mathrm{H}$ NMR, UV-VIS and SEM analysis of the sodium-lithium niobate nanostructures encapsulated into lignin and BSA showed that these nanostructures were well incorporated into the biopolymeric matrices. Sodium-lithium niobate 
nanostructures were well dispersed into albumin and were stabilized by the amino groups. There are four mass-loss events in the TG of sodium-lithium niobate nanostructures encapsulated lignin. The third and fourth events were observed at high temperature regions and the maximum degradations $\left(T_{\mathrm{m}}\right)$ were observed at $672{ }^{\circ} \mathrm{C}$ and $735{ }^{\circ} \mathrm{C}$ respectively. There are several mass-loss events in the TG of BSAencapsulated sodium-lithium niobate nanostructures. These steps are due to the denaturation of protein, decomposition of protein and the events at higher temperature regions corresponds to the change of crystal structure of sodium-lithium niobate nanostructures.

In this paper we present the synthesis and characterization of LNN ceramic structures which was prepared by sol-gel method. One of the main advantages of this method is that it follows the chemical method. Ceramic structures with appropriate particle size were prepared by the intelligently chosen heat-treatment method. The encapsulation of nano-sized ceramic structures into biopolymer matrices imparts biocompatibility to the system. The coupling of biomolecular entities and materials at the nanoscale has the potential to revolutionize many fields of science and technology, potentially having a significant impact on current biomedical technologies, nanoelectronics, and related areas.

\section{Acknowledgements}

This work was financially supported by the University Grants Commission, New Delhi, India (No. MRP(S)-987/10-11/KLMG027/UGC-SWRO, February 10, 2011), and DST, Government of India (No. SR/S1/OC-24/2006, October 26, 2006).

Open Access: This article is distributed under the terms of the Creative Commons Attribution Noncommercial License which permits any noncommercial use, distribution, and reproduction in any medium, provided the original author(s) and source are credited.

\section{References}

[1] Nitta T. Properties of sodium-lithium niobate solid solution ceramics with small lithium concentrations. J Am Ceram Soc 1968, 51: 623-630.

[2] Megaw HD. The seven phases of sodium niobate. Ferroelectrics 1974, 7: 87-89.

[3] Pardo L, Durn-Martin P, Mercurio J, et al. Temperature behaviour of structural, dielectric and piezoelectric properties of sol-gel processed ceramics of the system $\mathrm{LiNbO}_{3}-\mathrm{NaNbO}_{3}$. $J$ Phys Chem Solids 1997, 58: 1335-1339.

[4] Nobre MAL, Longo E, Leite ER, et al. Synthesis and sintering of ultra fine $\mathrm{NaNbO}_{3}$ powder by use of polymeric precursors. Mater Lett 1996, 28: 215-220.

[5] Popa M, Kakihana M. Synthesis and thermoanalytical investigation of an amorphous praseodymium citrate. $J$ Therm Anal Calorim 2001, 65: 281-293.

[6] Lanfredi S, Dessemond L, Rodrigues ACM. Dense ceramics of $\mathrm{NaNbO}_{3}$ produced from powders prepared by a new chemical route. $J$ Eur Ceram Soc 2000, 20: 983-990.

[7] Thielemans W, Wool RP. Butyrated kraft lignin as compatibilizing agent for natural fiber reinforced thermoset composites. Composites Part A 2004, 35: $327-338$.

[8] Ek M, Gellerstedt G, Henriksson G. Lignin. In Pulp and Paper Chemistry and Technology, Volume 1: Wood Chemistry and Biotechnology. Henriksson G, Ed. Berlin: Walter de Gruyter GmbH \& Co. KG., 2009.

[9] Xiao B, Sun XF, Sun RC. The chemical modification of lignins with succinic anhydride in aqueous systems. Polym Degrad Stab 2001, 71: 223-231.

[10] Peters T. All About Albumin: Biochemistry, Genetics, and Medical Applications. California, USA: Academic Press, 1996.

[11] Mathew TV, Kuriakose S. Studies on the antimicrobial properties of colloidal silver nanoparticles stabilized by bovine serum albumin. Colloids Surf B 2013, 101: 14-18.

[12] Hershey JWB. Translational control in mammalian cells. Annu Rev Biochem 1991, 60: 717-755.

[13] Simard JR, Zunszain PA, Hamilton JA, et al. Location of high and low affinity fatty acid binding sites on human serum albumin revealed by NMR drug-competition analysis. $J$ Mol Biol 2006, 361: 336-351.

[14] Sabatino P, Casella L, Granata A, et al. Synthetic chrysotile nanocrystals as a reference standard to investigate surface-induced serum albumin structural modifications. J Colloid Interface Sci 2007, 314: 389-397.

[15] Sabbioni G, Wild CP. Identification of an aflatoxin $\mathrm{G}_{1}$-serum albumin adduct and its relevance to the measurement of human exposure to aflatoxins. Carcinogenesis 1990, 12: 97-103.

[16] Ewaskiewicz JI, Devlin TM, Ch'ih JJ. The in vivo disposition of aflatoxin $\mathrm{B}_{1}$ in rat liver. Biochem Biophys Res Commun 1991, 119: 1095-1100.

[17] Prapitpongwanich P, Harizanova R, Pengpat K, et al. Nanocrystallization of ferroelectric lithium niobate in $\mathrm{LiNbO}_{3}-\mathrm{SiO}_{2}$ glasses. Mater Lett 2009, 63: 1027-1029. 